\title{
Quality control and insulation construction technology of exterior house
}

\section{paint decoration}

\author{
Yin Xizhu ${ }^{1}$, Liu Yalan ${ }^{1}$ \\ ${ }^{1}$ Northeast Forestry University, Harbin, Heilongjiang Province, 150040, China
}

Keywords: Wall insulation; energy; water; bonding

\begin{abstract}
The construction must seriously study material standards, and have knowledge of building materials, and fully understand the scope and use of properties of the coating was not to be careless with the wrong paint, applied over the interior facade. After the sun and rain, appeared in a short unexpected quality problems, not their own free, there is no scientific base paint is formulated so that both resulting in economic losses, rework brings trouble, affecting project quality and construction schedule. Strict control and eliminate noise. Electrical equipment should be used to strengthen the good fruit machine, no heat generated by the bridge, durability, does not account for the use of space, faster construction and other equipment maintenance, elimination of machine friction, collision caused by noise. Take advantage of night transport material, solve the surface cracking, hollowing and other quality problems, has good social effect material, vehicles can not whistle, reduce noise nuisance.
\end{abstract}

\section{Introduction}

Building exterior decoration varied architectural coatings is one of them, the reason to use it in all kinds of buildings, because it has a simple construction, colorful, soft, smooth lines, clear, can create multiple texture effects, easy maintenance and updating of advantages [1, 2]. However, if done incorrectly, or used for the coating properties or do not understand the grassroots handled properly, it will affect the quality of the coating and beautiful facades.Construction must understand design intent and other design documents, clarify the use of functions, priority through quality certification of products or green products. Prevent the use of fake and shoddy products, the incoming random checks of its varieties, color meets the requirements of design and construction, and should product performance test report and product certificate [3]. Classification of incoming stacked, identification, and person responsible for the establishment of the material site acceptance system, to ensure the good material quality [4].

Strengthening primary key is the quality of construction of grass-roots strength, smoothness and cleanliness. Thus, the moisture content of the grass-roots strength is an important indicator of the different types of coatings on the moisture content requirements are also different $[5,6]$. Brushing solvent-based coatings, the moisture content shall not exceed $8 \%$, brushing water-soluble paint grassroots moisture content not greater than $10 \%$, the moisture content of the wood must not be greater than $12 \%$. Therefore, controlling the moisture content of the requirements is to ensure that the paint adhesion and grassroots and grass-roots does not appear from the skin, hollowing, cracking and so on, should not rush period due to progress while ignoring the grassroots strength [7].

Primary coated surface flatness is poor, or if obvious then hew different surface roughness, spray, roller, brush to paint because the paint also uneven absorption, resulting in uneven facades color, easy 
to form a "painted face." Furthermore, the primary surface uneven, resulting putty on the granting of varying thickness, wet and dry uneven, is also vulnerable to the formation of local cracking and peeling. Thus, the primary surface should be smooth, solid, firm, should not have from the sand, cracks and loose and other defects. Primary pollution as there are floating off the ash, dirt, mold release agents, oil and other attachments, also due to poor adhesion of the coating with the primary cause appears veneer peeling, shedding, color and so on, which must ensure that the primary surface clean . Before brushing paint, according to the construction norms should be quality acceptance inspection, do not meet the requirements of the grass-roots level, for example, surface crazing, crisp, clean hollowing phenomena such as chisel and smooth with cement mortar calender let dry, ensure strong and solid grassroots level. There is mold growth in walls, wipe moldy place with $10 \%$ calcium hypochlorite solution, maintaining $24 \mathrm{~h}$, then washed thoroughly with water After drying, apply a primer.

\section{Construction environment}

Various paints must under certain temperature conditions to form a continuous film, so it requires high construction environment, conducive to proper temperature drying coating, film formation. If the environmental temperature is too low or too high, it will reduce the technical indicators paint will cause bad paint film formation that can not be done to produce a uniform surface coating crack, powder, water loss, seriously affecting appearance of the building and facing life $[8,9]$. Therefore, we must strictly control the construction paint the minimum allowable temperature and humidity. Construction environment temperature should choose paint works is $5 \sim 35{ }^{\circ} \mathrm{C}$, and have good ventilation, so that both speed up the conjunctiva process, but also beneficial to the health of operators.Exterior wall structure was shown in Figure 1.

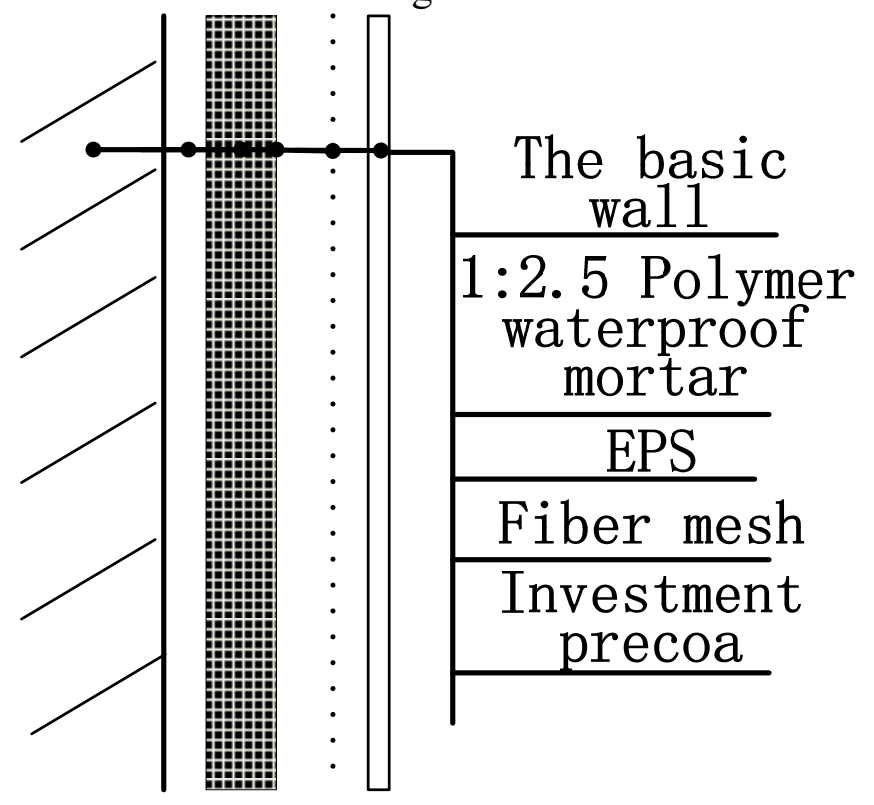

Figure 1.Exterior wall structure

With the development of new products, the type of coating is also increasing, especially for new products, technical standards, functions should be properly used as required instructions for construction, must act empirically. It should also be emphasized that that is not at the moment a film coating to complete, during which there is a process, it requires not only the construction meets the minimum construction temperature requirements, and after a period of time the construction should meet temperature requirements, select the appropriate the function is to ensure that the construction environment, construction, technical standard paint products to give full play.Construction workers must be ready to pre-construction, construction and technical management to make operators process quality technical disclosure. Coating species selected according to the requirements of design and 
construction, color. To avoid color, should be based on the requirements once an ample supply quantity, the deployment is complete, and fully stir up within the specified time, otherwise it will reduce its Technical indicators affecting the quality applied.

\section{Decoration materials}

Adhesive mortar: the special adhesive and ordinary portland cement mixed according to a certain weight ratio of polymer mortar, adhesive mortar basic technical performance are shown in Table 1.

Table 1. The Specification of Bonding mortar

\begin{tabular}{|c|c|c|}
\hline \multicolumn{2}{|c|}{ Item } & Specifications \\
\hline $\begin{array}{c}\text { Tensile bond } \\
\text { strength/MPa } \\
\text { (with cement mortar) }\end{array}$ & $\begin{array}{c}\text { original intensity } \\
\text { waterproof }\end{array}$ & $\begin{array}{l}\geq 0.70 \\
\geq 0.50\end{array}$ \\
\hline \multirow{2}{*}{$\begin{array}{l}\text { Tensile bond } \\
\text { strength/MPa } \\
\text { (with EPS) }\end{array}$} & original intensity & $\begin{array}{l}\geq 0.12 \text {, the breaking surface is on the } \\
\text { EPS }\end{array}$ \\
\hline & waterproof & $\begin{array}{l}\geq 0.12 \text {, the breaking surface is on } \\
\text { the EPS }\end{array}$ \\
\hline Operable & $e / h$ & $1.5 \sim 4.0$ \\
\hline
\end{tabular}

Expanded polystyrene board: flame retardant polystyrene foam board (ie, EPS board), the main properties are shown in Table 2.

Table 2. The Specification of EPS

\begin{tabular}{cc}
\hline Item & Specifications \\
\hline Conductivity $/[\mathrm{W} /(\mathrm{m} \cdot \mathrm{K})]$ & $\leq 0.041$ \\
Apparent Density $/(\mathrm{kg} / \mathrm{m} 3)$ & $18.0 \sim 25.0$ \\
Tensile strength in vertical direction/KPa & $\geq 0.10$ \\
Dimensional stability $/ \%$ & $\leq 0.30$ \\
Flammability & B2 \\
\hline
\end{tabular}

Alkali-resistant fiberglass mesh: the use of special materials designed Witt coated. Due to the displacement of the wall can be buffered, cracking causes a slight displacement of the polystyrene board, cement and resistance to alkaline attack. The main performance alkali-resistant grid cloth was shown in Table 3.

Table 3. The Specification of alkali-resistant fiber mesh

\begin{tabular}{cc}
\hline Item & Specifications \\
\hline Mass per unit area/(g/m2) & $\geq 145$ \\
Breaking strain/\% & $\leq 4.0$ \\
Alkali resistant breaking strength/(N/50mm) & $\geq 1200$ \\
Alkali resistant breaking strength retention/\% & $\geq 80$ \\
\hline
\end{tabular}

Front exterior insulation construction, outside window and door openings should be acceptance, hole size, quality and location should meet the design requirements, the door frame or auxiliary frame should be installed, and the need to do waterproofing. Projecting wall fire ladder, the water pipes, pipelines and air conditioners into the family of embedded parts, connectors should be installed, go 
out and set aside insulation system thickness. In addition to the design requirements, the wall should not be set aside holes and install scaffolding eye.

\section{Quality control}

Wall energy-saving projects shall pass evaluation and design documents for examination and approval of construction plan construction; pre-construction site should be using the same materials and production process model element, the construction can be carried out after confirmation parties concerned. During external insulation construction and after the completion within $24 \mathrm{~h}$, and the grassroots ambient air temperature should not be lower than $5{ }^{\circ} \mathrm{C}$. Summer should avoid sun exposure. 5 more windy weather and rain not construction.

Building height of $20 \mathrm{~m}$ above shall be individual design requirements, construction and insulation system level synchronization fire buffer zone set up isolation layers shall comply with the requirements. External wall insulation works should be in the main structure and the quality of the grass-roots acceptance of construction, the construction process should be timely QA covert project acceptance and acceptance inspection lot shall be carried out after the completion of the construction of energy-saving wall sub-project acceptance. Primary wall quality inspection: primary wall deflection should not exceed L / 240 center of the floor height), the base surface should be within the range of $2.0 \mathrm{~m}$ flatness of not more than $6 \mathrm{~mm}$, finishing layer of cement mortar wall and the wall must be bonded firmly, no delamination, hollowing and cracks.

\section{Summary}

Architectural coatings market variety, scope and conditions vary. It is commonly used paint, but also the external walls of the points. Therefore, the construction must seriously study material standards, and have knowledge of building materials, and fully understand the scope and use of properties of the coating was not to be careless with the wrong paint, applied over the interior facade. After the sun and rain, appeared in a short unexpected quality problems, not their own free, there is no scientific base paint is formulated so that both resulting in economic losses, rework brings trouble, affecting project quality and construction schedule. Strict control and eliminate noise. Electrical equipment should be used to strengthen the good fruit machine, no heat generated by the bridge, durability, does not account for the use of space, faster construction and other equipment maintenance, elimination of machine friction, collision caused by noise. Take advantage of night transport material, solve the surface cracking, hollowing and other quality problems, has good social effect material, vehicles can not whistle, reduce noise nuisance.

\section{References}

[1] Taylor, T., Counsell, J., \& Gill, S. (2013). Energy efficiency is more than skin deep: Improving construction quality control in new-build housing using thermography. Energy and Buildings, 66, 222-231.

[2] Bomberg, M., Gibson, M., \& Zhang, J. (2015). A concept of integrated environmental approach for building upgrades and new construction: Part 1-setting the stage. Journal of Building Physics, 38(4), 360-385.

[3] A. Tarighat, M. Sadek, A. H. Sayed, "A multi User Beamforming Scheme for Downlink MIMO Channels based on Maximizing Signal-to-Leakage Ratios", IEEE International Conference on Acoustics, Speech, and Signal Processing, pp. 1129-1132, 2005. 
[4] J.van de Beek,O. Edfors, M. Sandell, S. Wilson, P. Borjesson, "On Channel Estimation in OFDM System", in Proceedings of the IEEE Vehicular Technology Conference, pp. 815-819, 1995.

[5] K.Wong, R. Cheng, K. B. Letaeif, R. D. Murch, "Adaptive antennas at the mobile and base stations in an OFDM/TDMA system”, IEEE Transactions on Communications, vol. 49, no.1, pp. 195-206, 2001.

[6] M. Sadek, A. Tarighat, A. H. Sayed, "Active Antenna Selection in multi-user MIMO Communications," IEEE Transactions on Signal Processing, vol. 55, no. 4, pp. 1498-1510, 2007.

[7] Zhu Yazhou, Zheng Guoxin, Rui Yun, , Li Mingqi, "A Novel Distributed Precoding Scheme Based on THP for Downlink Multi-Cell Multi-User OFDMA Wireless Systems", IJACT: International Journal of Advancements in Computing Technology, vol. 5, no. 9, pp. 213-220, 2011.

[8] Raore Soungalo, Li Renfa and Zeng Fanzi, "Evaluating and Improving Wireless Local Area Networks Performance", IJACT: International Journal of Advancements in Computing Technology, vol. 3, no. 2, pp. 156-164, 2011.

[9] Loomis H, Pettit B. Measure Guideline: Deep Energy Enclosure Retrofit for Double-Stud Walls[R]. National Renewable Energy Laboratory (NREL), Golden, CO (United States), 2015. 